\title{
El problema del nominalismo en la definición spinozista del alma
}

\author{
RODRIGO SEBASTIÁN BRAICOVICH \\ Escuela de Filosofía \\ Facultad de Humanidades y Artes \\ Universidad Nacional de Rosario (Argentina) \\ rbraicovich@yahoo.com.ar
}

\begin{abstract}
Resumen: La respuesta que demos a la problemática del nominalismo en la obra de Baruch Spinoza determina en forma decisiva las posibilidades de responder satisfactoriamente a la pregunta por la naturaleza humana. Dictaminar (junto con numerosos intérpretes contemporáneos) que el spinozismo se construye sin concesiones sobre principios nominalistas implica sustraer todo fundamento ontológico a las consideraciones acerca de la natura humana, piedra de toque de la deducción spinozista de los afectos y de las estrategias terapéuticas que señalan el camino hacia la beatitudo. Nuestra intención, por el contrario, consistirá en señalar el componente necesariamente universal que subyace bajo la psicología spinozista, para lo cual habremos de señalar ciertos aspectos centrales en cuanto a la problemática de los géneros de conocimiento, así como respecto de la teoría spinozista de la definición.

Palabras clave: Spinoza, nominalismo, esencialismo, naturaleza humana
\end{abstract}

\begin{abstract}
The answer that I give to the problem of nominalism in the work of Baruch Spinoza determines in a decisive fashion the possibilities of replying affirmatively to the question about human nature. To decide (along with a large number of contemporary interpreters of Spinoza's philosophy) that the latter is ultimately built upon nominalistic principles forces us to do away with every ontological foundation of human nature, touchstone concept of Spinoza's deduction both of the affects and of the therapeutic strategies that show the way to beatitudo. My aim, on the contrary, consists in bringing to light the necessarily universal component that underlies Spinoza's psychology. Aiming at this, I review not only certain key aspects regarding the problem of the kinds of knowledge, but also the Spinozistic theory of definition.
\end{abstract}

Key words: Spinoza, nominalism, essentialism, human nature

\section{Los géneros de conocimiento y el nominalismo}

¿Es nominalista Spinoza? La respuesta que demos a esta pregunta esconde parcialmente la clave para la interpretación de numerosas proyecciones de la ética spinozista: en efecto, si interpretamos que las nociones universales no son más que ficciones que pertenecen al orden de la imaginación, ${ }^{1}$ no poseyendo realidad extra mentem alguna, entonces

1 “Todas las nociones por las cuales suele el vulgo explicar la naturaleza son sólo modos de imaginar, y no indican la naturaleza de cosa alguna, sino sólo la 
toda especulación acerca de la naturaleza o esencia humana (concepto necesariamente universal) carece de sentido. ${ }^{2}$ Será nuestra intención demostrar, por el contrario, que el concepto de naturaleza humana que recorre la totalidad de la ética spinozista no constituye un mero flatus vocis, carente de fundamentos universales, ${ }^{3}$ sino que se presenta como un modelo que pretende sustituir las construcciones arbitrarias de la imaginación (no carentes de usos teológico-políticos) mediante una nueva concepción deducida a partir de las leyes inmutables que rigen a los atributos y sus modificaciones. En este sentido, si bien es evidente que la ética spinozista no puede ser reducida a un decálogo de officia/ kathékonta, instalar un núcleo gnoseológico nominalista en el seno de la obra del holandés implica cercenar toda posible proyección de una ética que se pretende necesaria, eterna y fundada en una percepción de las cosas "tal como son en sí (ut in se sunt)". 4

A pesar de esto, numerosos comentaristas contemporáneos han insistido sobre el nominalismo spinozista como clave de bóveda para comprender el problema de la inmanencia. ${ }^{5}$ Según esta línea de interpretación, el antirrealismo de Spinoza constituiría el único soporte contextura de la imaginación; y, pues tienen nombres como los que tendrían entidades existentes fuera de la imaginación, no las llamo entes de razón, sino de imaginación" (ET, I, apéndice). En lo sucesivo me basaré en Baruch Spinoza, Opera, Carl Winters, Heidelberg, 1925, apoyándome en las siguientes traducciones: Ética demostrada según el orden geométrico, traducción, introducción y notas de Vidal Peña, Orbis, Buenos Aires, 1984; Tratado breve, traducción, prólogo y notas de Atilano Domínguez, Alianza, Madrid, 1990; Tratado de la reforma del entendimiento y otros escritos, traducción, notas y comentario de Lelio Fernández y Jean Paul Margot, Universidad Nacional de Colombia, Colombia, 1984; Tratado teológico-político, traducción, introducción, notas e índices de Atilano Domínguez, Alianza, Madrid, 1986; Tratado político, traducción y estudio preliminar de Enrique Tierno Galván, Tecnos, Madrid, 1996.

${ }^{2}$ Si así fuera, como señala Haserot: "Dios deviene esencialmente incognoscible y la totalidad de la filosofía de la $E T$ toma la forma de una construcción mental de acuerdo con la cual conjeturamos una realidad que, en su verdadera naturaleza, yace más allá de nuestro alcance. Los atributos devienen categorías primarias del entendimiento, y la filosofía, en esta interpretación, deviene esencialmente epistemología, dado que la ontología es imposible" (F.S. Haserot, "Spinoza and the Status of Universals", pp. 43-44; la traducción es nuestra).

${ }^{3}$ En palabras del propio Spinoza que remiten a la disputa entre voluntarismo y ejemplarismo: "Si pudiéramos concebir que [las nociones comunes] pudieran ser cambiadas por algún poder [...] no podríamos estar ciertos jamás de cosa alguna" (TTP, p. 84. Se cita de acuerdo a la paginación de B. Spinoza, Opera, ed. cit.).

${ }^{4}$ ET, II, 44.

${ }^{5}$ Vid., entre otros, J.L. Fuentes Herreros, "Spinoza: una filosofía barroca", p. 12; A. Gilead, "Spinoza's Principium Individuationis and Personal Identity", p. 42; Paul 
ontológico posible sobre el cual afirmar el proyecto de destitución de toda instancia trascendente y lógicamente anterior al actuar humano. Tal interpretación encuentra fundamentos numerosos en la obra de Spinoza; ${ }^{6}$ en lo que a nuestro tema inmediato concierne, parece suficiente citar un célebre pasaje de ET:

El cuerpo humano, por ser limitado, es capaz de formar, distinta y simultáneamente, sólo un cierto número de imágenes; si ese número es sobrepasado, las imágenes empezarán a confundirse, y si el número de imágenes que el cuerpo es capaz de formar distinta y simultáneamente es sobrepasado con mucho, se confundirán todas completamente entre sí [...]. De causas similares han surgido también las nociones llamadas universales, como 'hombre', 'caballo', 'perro', etc., a saber: porque en el cuerpo humano se han formado simultáneamente tantas imágenes - por ejemplode hombres, que la capacidad (vim) de imaginar queda, si no del todo, sí lo bastante desbordada (superent) como para que el alma no pueda imaginar las pequeñas diferencias entre los seres singulares (como el color o el tamaño de cada uno, etc.), ni tampoco el número preciso de ellos, y sólo imagine de un modo distinto aquello en que todos concuerdan (convenit) en la medida en que afectan al cuerpo (ya que es en virtud de ello como cada cosa singular afecta sobre todo al cuerpo), y eso es lo que el alma expresa con la palabra "hombre", predicándolo de infinitos seres singulares. (ET, II, 40, esc. i)

De esta suerte, la noción de hombre no poseería mayor realidad que una existencia in mentem, dependiente del sujeto que la forma y de carácter estrictamente relativo. Si bien la importancia de esta problemática se revelará en todas sus dimensiones al abordar el estatus ontológico de las nociones de bonus y malus y sus consecuencias prácticas para la acción correcta, de la solución definitiva de esta doctrina depende la siguiente pregunta: si sólo "las cosas particulares y sólo ellas tienen causa, y no las generales, que no son nada", 7 ¿qué estatus podemos/debemos asignar a la natura humana? En otras palabras, ¿es posible trasladar el argumento nominalista a la pregunta por la existencia del alma? La respuesta a esta pregunta depende, no obstante, de una clarificación

D. Eisenberg, "How to Understand De Intellectus Emendatione"; J. Friedman, "An Overview of Spinoza's 'Ethics' ”, pp. 67-106; C. Gebhardt, Spinoza, p. 102.

${ }^{6}$ Cfr. especialmente TB, I, 5.7-9 y I, 10.3; TRE §§ 88-90; ET, III, 39, esc.; IV, prefacio; Cartas XIX y XXI.

${ }^{7}$ TB, I, 5.7; las cursivas son nuestras. Cfr. ET, II, 10: "A la esencia del hombre no pertenece el ser (esse) de la substancia, o sea, no es una substancia lo que constituye la forma del hombre." 
(necesariamente esquemática) de la problemática de los géneros de conocimiento esbozados en la obra de Spinoza. De ella se derivarán una serie de caminos que permitirán resolver la pregunta no sólo acerca del posible nominalismo de Spinoza, sino también acerca de la coherencia propia de una ética deducida a partir de instancias universales.

A pesar de las divergencias e inconsistencias parciales que presenta la obra de Spinoza al momento de definir los géneros de conocimiento, no creemos necesario ingresar en la problemática puntual acerca de las variaciones manifestadas por el autor. Creemos, por el contrario, que existe una matriz común que subyace a las variaciones registradas, manifiestas en mayor medida en lo referido al tercer género de conocimiento en el pasaje desde $T B$ a TRE, y a la terminología utilizada para designar el producto intelectual de la razón. Si bien no puede ponerse en duda el hecho de que el descubrimiento de las "nociones comunes" rectifica el horizonte de los géneros de conocimiento, esto no significa, como pretende Deleuze, que "transforme toda la concepción spinozista de la Razón", 8 sino que se trata más bien de una sistematización bajo nuevos ejes conceptuales, que incorpora los desarrollos anteriores, sin implicar contradicción alguna con el núcleo ya esbozado en TB y TRE. Por lo pronto, una caracterización mínima del esquema podría ser extraída de ET:

Percibimos muchas cosas y formamos nociones universales: primero, a partir de las cosas singulares, que nos son representadas por medio de los sentidos, de un modo mutilado, confuso y sin orden respecto del entendimiento (ad intellectum repræsentatis): y por eso suelo llamar a tales percepciones "conocimiento por experiencia vaga"; segundo, a partir de signos; por ejemplo, de que al oír o leer ciertas palabras nos acordamos de las cosas, y formamos ciertas ideas semejantes a ellas, por medio de las cuales imaginamos esas cosas. En adelante, llamaré, tanto al primer modo de considerar las cosas como a este segundo, "conocimiento del primer género", "opinión" o "imaginación"; tercero, a partir, por último, del hecho de que tenemos nociones comunes e ideas adecuadas de las propiedades de las cosas; y a este modo de conocer lo llamaré "razón" y "conocimiento del segundo género". Además de estos dos géneros de conocimiento, hay un tercero - como mostraré más adelante-, al que llamaremos "ciencia intuitiva". Y este género de conocimiento progresa (procedit), a partir de la idea adecuada de la esencia formal de ciertos atributos de Dios, hacia el conocimiento adecuado de la esencia de las cosas. (ET, II, 40, esc. ii)

${ }^{8}$ G. Deleuze, Spinoza: filosofía práctica, p. 125.

Diánoia, vol. LIII, no. 60 (mayo 2008). 
Varios elementos surgen a la luz en este pasaje que habrán de determinar la totalidad del acercamiento spinozista a la definición del alma. En primer lugar, estos denominados géneros de conocimiento, amén de su enraizamiento en una clasificación gnoseológica que se remonta hasta Aristóteles, en modo alguno representan facultades diversas del alma; es decir, vías de acceso diversas hacia un mismo fenómeno: si consideramos que el elemento común que reúne a los dos primeros géneros es el hecho de que ambos consisten en procesos divergentes de formación de nociones universales, ${ }^{9}$ se hace evidente que, antes que formas de acceder al fenómeno, se trata más bien de dos formas diversas mediante las cuales el sujeto se posiciona y opera ante el mismo. De allí la imposibilidad de sustraerse a toda consideración gnoseológica al momento de abordar la definición del alma y de las pasiones: "el conocimiento tiene un estatuto existencial, genera un modo específico de estar en el mundo, de relacionarnos con los otros, con las cosas y con nosotros mismos". ${ }^{10} \mathrm{Si}$ bien el primero y el segundo géneros reciben denominaciones que permitirían interpretarlos como facultades diversas, se hace evidente que no implican solamente el proceso mediante el cual accedemos al conocimiento de los cuerpos que afectan nuestro cuerpo, sino también la scientia elaborada a partir de tales afecciones; es decir, los efectos que se siguen necesariamente en el alma de la presencia de ciertas ideas.

El primer género de conocimiento, la opinión, no es simplemente una afección de la exterioridad sobre nuestro cuerpo, durante la cual el alma permanecería en estado puramente pasivo, sino que implica una operación de generalización por parte del alma a partir del material ofrecido por tales afecciones. ¿Cuál es el criterio al que recurre la opinión para establecer tales generalizaciones? Precisamente el orden y concatenación mediante los cuales los cuerpos externos afectan al propio cuerpo, los cuales se distinguen "de la concatenación de ideas que se produce según el orden del entendimiento, mediante el cual el alma percibe las cosas por sus primeras causas, y que es el mismo en todos los hombres". ${ }^{11}$ En segunda instancia, dado que toda imagen en el alma de un cuerpo exterior — considerada por sí misma y en forma aislada-

${ }^{9}$ Como intentaremos mostrar, es el grado de universalidad involucrado inclusive en las nociones comunes el que permite comprender que la ética spinozista no se reduce a una serie de observaciones de carácter empírico y probabilístico, sino que constituye una proyección a partir de demostraciones de carácter necesario.

${ }^{10}$ D. Tatián, La cautela del salvaje, pp. 118-119. Cfr., asimismo, G. Deleuze, Spinoza: filosofía práctica, op. cit., p. 80.

${ }^{11}$ ET, II, 18, esc. 
constituye una idea inadecuada (en cuanto que por ser exterior no se explica por la sola esencia del alma, sino que es como una conclusión sin premisas, un efecto sin el conocimiento adecuado de la causa que lo ha producido), ${ }^{12}$ toda operación de construcción de nociones universales a partir de las mismas deberá, por extensión, estar signada por esa misma inadecuación. De esta suerte, los universales formados mediante la opinión serán inadecuados y dependientes del orden y concatenación de las afecciones.

Que a este género de nociones universales corresponde la totalidad de los conceptos sobre los que se han construido históricamente las religiones de la superstición excede nuestros objetivos y será tarea del TTP demostrarlo. Por lo pronto creemos suficiente señalar ciertos elementos clave: si bien los universales que surgen de la opinión se fundan, en última instancia, en una operación sensible (en cuanto que proceden de una imagen confusa que, a su vez, toma su origen y orden del orden de las afecciones del cuerpo) e inadecuada - por lo que generalmente conducen al error-, no constituyen en absoluto ilusiones aisladas y carentes de estructuración recíproca. A pesar de que, como sostiene Haserot, por el hecho de ser inadecuados, estos universales "no se mantienen unidos (are not held together) por ninguna lógica inherente [y] no están conectados por ningún enlace deductivo", ${ }^{13}$ esto sólo es válido en tanto consideramos a tales nociones en sí mismas; es decir, en cuanto a su conformación interna, y no en cuanto al encadenamiento múltiple que cada universal construye respecto de otros universales: como señala François Galichet, "en cuanto [...] a su organización [...] vemos a Spinoza utilizar el mismo vocabulario que utiliza respecto del conocimiento verdadero: ellas [las ideas inadecuadas] son susceptibles de 'deducciones', se articulan según una cadena de consecuencias ne-

${ }^{12}$ Contra esta definición por demás esquemática, cabe recordar que ya desde el $T R E$, Spinoza ha tipificado la idea inadecuada bajo dos formas: aquella que no da cuenta de "cómo y porqué algo es o ha sido hecho" (§ 85) y aquella que "afirma de alguna cosa algo que no está contenido en el concepto" (§ 72). No tener en cuenta esta doble posibilidad ha motivado, por ejemplo, un extenso trabajo realizado por François Galichet ("Le Problème de l'illusion chez Spinoza", pp. 1-19), consagrado íntegramente a demostrar la insuficiencia de la primera de estas definiciones para dar cuenta de los distintos tipos de ilusión que subyacen a la filosofía y a la religión. Bien es cierto que tal definición resulta ser, a fin de cuentas, la más operativa en el marco de ET; aun así, creemos evidente que la segunda de ellas está presente en la totalidad de las argumentaciones spinozistas respecto del problema de la relación entre imaginación y existencia.

${ }^{13}$ F. Haserot, op. cit., p. 52; la traducción es nuestra. 
cesarias a partir de una premisa originaria". ${ }^{14}$ En todo caso, para comprender las consecuencias de esta estructuración propia de las ideas inadecuadas será preciso clarificar las características esenciales de los géneros de conocimiento restantes.

¿Qué sucede en el pasaje del primero al segundo género de conocimiento? ¿Se trata en rigor de un pasaje, de una evolución sin discontinuidades visibles? Los comentarios derivados de la tradición deleuziana han tomado como cierto que efectivamente lo que encontramos aquí es una transición gradual de uno a otro género. Esta interpretación se soporta sobre dos hipótesis centrales para Deleuze: la primera de ellas consiste en comprender que "la imaginación capta como efectos exteriores de los cuerpos entre sí lo que la noción común explica mediante las relaciones internas constitutivas". ${ }^{15}$ Sin embargo, asentir a esta proposición —en sí misma correcta- no implica conceder una relación de continuidad entre el primero y el segundo géneros de conocimiento, dado que la imaginación referida por Deleuze no es privativa del primer género de conocimiento: la imaginación -0 , mejor, la presencia de imágenes en el alma - es el datum sobre el que operan ambos géneros, pero el primero de ellos es más que esa simple presencia: es la formación (bajo una modalidad específica) de universales a partir de tales imágenes; universales de los que la razón debe desembarazarse en el proceso de construcción de nociones comunes.

Un segundo argumento ofrecido por Deleuze afirma que

cuando nos encontramos con cuerpos que convienen con el nuestro, no poseemos aún las ideas adecuadas de estos cuerpos ni de nosotros mismos, pero experimentamos pasiones alegres (aumento de nuestra potencia de acción) que todavía pertenecen al primer tipo, pero inducen ya en nosotros la formación de la idea adecuada de lo que es común a estos cuerpos y al nuestro. ${ }^{16}$

Si bien esta interpretación se asienta, según entendemos, sobre varias premisas cuestionables, por el momento sólo nos interesa destacar la problemática implícita en esta transición: si el primer género de conocimiento opera mediante ideas inadecuadas, y dado que "las ideas inadecuadas y confusas se siguen (cosequuntur) unas de otras con la misma necesidad que las ideas adecuadas", ${ }^{17}$ ¿cómo es posible que a

${ }^{14}$ F. Galichet, op. cit., p. 9; la traducción es nuestra. Cfr., asimismo, L. Bove, "La Théorie du langage chez Spinoza", p. 19.

${ }^{15}$ G. Deleuze, Spinoza: filosofía práctica, op. cit., p. 127.

${ }^{16}$ Ibid., pp. 81-82.

${ }^{17}$ ET, II, 36. 
una idea inadecuada siga una idea adecuada? Es decir, ¿cómo es posible el ingreso en el segundo género de conocimiento?

Si bien estas preguntas sólo pueden ser resueltas analizando en profundidad el proceso de formación de las pasiones (lo cual excede los límites de este trabajo), cabe señalar ciertas características definitorias del segundo género de conocimiento: en primer lugar, como referíamos anteriormente, la razón - a diferencia del primer género- forma nociones universales a partir "del hecho de que tenemos nociones comunes e ideas adecuadas de las propiedades de las cosas". ${ }^{18}$ En cuanto al primero de estos productos, y partiendo de las escasas especificaciones acerca de las nociones comunes que encontramos en $E T$, podemos retener dos indicaciones fundamentales: en primer lugar, tales nociones - de las cuales algunas son más útiles que otras- "son los fundamentos de nuestro raciocinio (ratiocinii)"; ${ }^{19}$ en segundo lugar, no implican tiempo, sino eternidad, ${ }^{20}$ es decir, su idea no involucra ningún tipo de relación con la duración, sino que expresan una comunidad entre el cuerpo afectante y el cuerpo afectado que posee características eternas, universales, necesarias y necesariamente verdaderas. ${ }^{21} \mathrm{Si}$ bien estas nociones comunes expresan precisamente aquello común a todos los individuos involucrados, tal comunidad procede no de una cualificación sensible ni de una pertenencia a géneros y especies comunes, sino de "concordancias, diferencias y oposiciones (convenientias, differentias et oppugnantias)" que son siempre relativas a la preservación del ser. ${ }^{22}$ En cuanto a las ideas adecuadas referidas por la definición citada de los productos del segundo género de conocimiento, la especificación complementaria que afirma que se trata de ideas adecuadas de las propiedades de las cosas, permite comprender la enmienda que ha sufrido la caracterización de la razón en la $E T$ a partir de la introducción de las nociones comunes. Si el TRE - en cuyo análisis las nociones comunes no desempeñan papel alguno- definía las operaciones racionales como la sola producción de ideas adecuadas, la especificación introducida por ET permite comprender esta nueva modalidad: así como toda noción común es necesariamente adecuada, toda idea adecuada es -inversamente- una noción común; es decir, una expresión adecuada de aquello que hay de común entre el alma y el objeto que la afecta.

${ }^{18} E T$, II, 40, esc. ii.

${ }^{19}$ ET, II, 40, esc. i.

${ }^{20}$ Cfr. ET, II, 44, cor. ii, dem.

${ }^{21}$ Cfr. ET, II, 44.

${ }^{22}$ ET, II, 29, esc.

Diánoia, vol. LIII, no. 60 (mayo 2008). 
Esta equivalencia entre ideas adecuadas y nociones comunes -inexistente hasta la redacción de $E T$ - permitirá superar la escisión (todavía presente hasta cierto punto en TB y TRE) entre gnoseología y ética, entre el proceso de formación de las ideas en el alma y la construcción de estrategias éticas que permitan perseverar en el ser. Sin embargo, si la necesaria adecuación de las nociones comunes asegura un conocimiento necesariamente verdadero de aquello que es común entre los cuerpos, la razón no puede dar cuenta de aquello que diferencia específicamente a cada uno de los modos finitos, ${ }^{23}$ tarea que será propia de la scientia intuitiva.

\section{El tercer género de conocimiento}

El ingreso en el tercer género de conocimiento parece a todas luces presuponer las conquistas del segundo: "El esfuerzo o el deseo de conocer las cosas según el tercer género de conocimiento no puede surgir (oriri) del primer género, pero sí del segundo." ${ }^{24}$ La necesidad de esta progresión se hace manifiesta en la definición misma de scientia intuitiva, la cual "progresa (procedit), a partir de la idea adecuada de la esencia formal de ciertos atributos de Dios, hacia el conocimiento adecuado de la esencia de las cosas". ${ }^{25}$ Sin embargo, el desglosamiento de esta definición en las tres instancias que la componen permite traer a la luz el carácter ambiguo de esta dependencia de la intuición respecto de la razón. En efecto, si bien el primero de los tres momentos (posesión de una idea adecuada) sólo es posible una vez que hemos ingresado en el segundo género (sólo la razón puede producir ideas adecuadas/nociones comunes), el objeto de esa idea parece establecer una nueva fisura en la transición entre los géneros de conocimiento: la idea adecuada de la esencia formal de ciertos atributos de Dios presupone poseer una idea adecuada cuya esencia objetiva sea precisamente Dios. ¿Es esto posible? ¿Es posible que la razón llegue por sus solas fuerzas a la idea (adecuada) de Dios? Por otra parte, el tercer momento de la definición citada excede en forma visible las capacidades de la razón: si ésta sólo opera con nociones comunes/ideas adecuadas, el conocimiento adecuado de las esencias de las cosas trasciende el plano de la comunidad para ingresar en el de la distinción específica. En otras

23 "Los fundamentos de la razón son nociones que explican lo que es común a todas las cosas, y que no explican la esencia de ninguna cosa singular" (ET, II, 44, cor. II, dem.).

${ }^{24} E T, \mathrm{~V}, 28$.

${ }^{25}$ ET, II, 40, esc. ii. Cfr. asimismo V, 25, dem. 
palabras, si la razón sólo atiende a lo común, es propio de la scientia intuitiva concebir las esencias en cuanto instancias singulares. En este sentido, podemos constatar un primer motivo para establecer una ruptura efectiva entre ambos momentos, al menos en cuanto a que, como ya indicaba $T B$, la razón "nos muestra qué le corresponde ser a la cosa, pero no qué es en realidad". ${ }^{26}$ Esto es, la razón opera con nociones comunes e ideas adecuadas que expresan aquello que es común a los cuerpos afectados, pero que - por sí mismas- no nos permiten acceder $\mathrm{ni}$ al conocimiento de la totalidad en la que se inscriben los modos, $n i$ a la esencia particular de cada uno de los mismos. ${ }^{27}$

La comprensión de estos dos últimos momentos (acceso a la idea adecuada de Dios y conocimiento de las esencias de las cosas singulares) sólo puede alcanzarse despejando ciertos equívocos recurrentes en la literatura secundaria sobre el autor: si el tercer género de conocimiento se define por ser una scientia intuitiva y, en cuanto tal, como afirmaba $T B$, "no está en nosotros en virtud de la deducción de otra cosa, sino de la manifestación inmediata del objeto mismo al entendimiento", ${ }^{28}$ se vuelve impostergable una pregunta: ¿qué significa precisamente esta manifestación inmediata del objeto? Más aún, ¿cuál es el objeto específico de esta intuición? En principio, es necesario señalar que la captación inmediata de la idea adecuada de Dios no equivale a una inmersión mística en la totalidad — como por momentos parece desprenderse del $T B-,{ }^{29}$ sino que implica un doble movimiento: 2) la comprensión del carácter no sustancial de los modos a partir de 1) la comprensión adecuada de la esencia de Dios.

Esta determinación de la intuitio como movimiento complejo (que comprende como su objeto, como señala Spinoza con insistencia, "sui et Dei et rerum") ${ }^{30}$ es esencial para comprender la imposibilidad de establecer una cercanía con la escolástica y el platonismo: la intuición no conduce a una contemplación extática de la divinidad en cuanto unidad supramodal, sino que proyecta un retorno sobre las modificaciones que

${ }^{26} \mathrm{~TB}, \mathrm{II}, 4.2$.

27 "Aquello que es común a todas las cosas, y que está igualmente en la parte y en el todo, no constituye la esencia de ninguna cosa singular" (ET, II, 37).

${ }^{28}$ TB, II, 22.1 .

${ }^{29}$ Así lo interpreta Galichet, haciéndolo extensivo a la totalidad de la filosofía spinozista: "En la medida en que el individuo, para ser, tiende a devenir una parte cada vez más grande de este entendimiento infinito, tiende a identificarse con él, a no conocerse más que en su relación con él como una parte del mismo - por lo tanto, a desdibujarse como individuo distinto, finito, limitado" (F. Galichet, op. cit., p. 2; la traducción es nuestra).

${ }^{30}$ ET, V, 39, esc. y V, 42, esc.

Diánoia, vol. LIII, no. 60 (mayo 2008). 
permite comprenderlas como singularidades determinadas en una estructura causal. En otras palabras, y aquí encuentra su obstáculo máximo toda interpretación mística de la gnoseología spinozista, el camino de la filosofía no es simplemente - como pretende Caillois- "el itinerario filosófico que va de Dios a Dios", ${ }^{31}$ sino el itinerario que va de Dios a las esencias particulares, concretas y determinadas que constituyen cada modo finito - aun cuando cada modo sea, en última instancia, una modificación de un atributo divino, y por ende, de Dios. En palabras de Syliane Charles: "Lo que importa es ver que todo conocimiento es conocimiento de lo que existe, y que lo que existe siempre se presenta a sí mismo bajo una forma modificada, finita." 32 En suma, si el tercer género de conocimiento no se agota en la contemplación de la divinidad, sino que tal contemplación deviene el momento inicial para la comprensión final de los modos finitos, el conocimiento de Dios sólo constituye el summum bonum de los modos finitos en tanto permite comprenderse precisamente como modo, esto es, adecuadamente: "La suprema virtud del alma consiste en conocer a Dios, o sea (sive), entender las cosas según el tercer género de conocimiento."33

Sin embargo, si esto alcanza para despejar el error místico en la interpretación de la obra de Spinoza, todavía no hemos solucionado el momento lógico que lo precede; es decir, cómo llegamos a un conocimiento adecuado de Dios. Al analizar la definición dada por ET de este tercer género, mencionábamos como un primer motivo de ruptura con respecto a la razón el hecho de que la idea adecuada de Dios (condición previa para poseer una idea adecuada de la esencia formal de ciertos atributos de Dios) sea el escalón inicial del tercer género de conocimiento, precisamente por ser una idea que no puede ser deducida de ninguna idea (por adecuada que sea) que tenga como esencia objetiva un modo finito. Contrariamente a esto, Deleuze ha ofrecido una interpretación

${ }^{31}$ R. Caillois, "Introduction" a Baruch Spinoza, OEuvres Completes, p. 31; la traducción es nuestra.

${ }^{32}$ S. Malinowski-Charles, "The Circle of Adequate Knowledge: Notes on Reason and Intuition in Spinoza", p. 148 (la traducción es nuestra). No obstante la corrección de esta síntesis, Charles ha pretendido anular la ruptura que suele establecerse (fundamentalmente en la tradición anglosajona derivada de la obra de Harry Wolfson) entre razón e intuición, argumentando que se trata "en realidad del mismo conocimiento, sólo que bajo dos modalidades distintas", y que "los dos conocimientos deben siempre darse juntos" (p. 142). La fundamentación de esta parcial superposición entre razón e intuición remite, sin embargo, a una argumentación dialéctica (y hegeliana) que difícilmente pueda ser aceptada como válida; menos aún como necesaria para comprender las relaciones entre razón e intuición.

${ }^{33}$ ET, V, 27, dem. 
inversa que parece haberse trasformado en canónica para numerosos comentadores de la obra de Spinoza: ${ }^{34}$

Las nociones comunes nos conducen necesariamente a la idea de Dios. La idea de Dios sirve incluso como la noción común más general, puesto que expresa lo que es común a todos los modos existentes, a saber, que son en Dios y son producidos por Dios. [Sin embargo] la idea de Dios no es en sí misma una noción común [...]: es precisamente porque comprende la esencia de Dios, y no funciona como noción común sino en relación a la composición de los modos existentes. Así pues, cuando las nociones comunes nos conducen necesariamente a la idea de Dios, nos llevan a un punto en el que todo bascula, y en el que el tercer tipo nos descubrirá la correlación de la esencia de Dios y de las esencias singulares de los seres reales. ${ }^{35}$

Las dificultades implícitas en esta argumentación son evidentes: que las nociones comunes nos conduzcan a la idea de Dios significa que existe un proceso de inferencia deductiva, lo cual establece abierta contradicción con la definición misma de sustancia, precisamente aquello que "es en sí y se concibe por sí, esto es, aquello cuyo concepto, para formarse, no precisa del concepto de otra cosa". ${ }^{36}$ Por otra parte, si las nociones comunes ofrecen el tránsito natural hacia la idea de Dios, ¿por qué habría conservado Spinoza la terminología intuicionista (por demás equívoca, es cierto, y anclada en una tradición con la que intenta por todos los medios producir una ruptura definitiva)? Es evidente que esta pregunta sólo posee sentido en tanto se acepte la interpretación continuista $^{37}$ entre los dos géneros superiores de conocimiento, interpretación que, en definitiva, encuentra una barrera constante a lo largo

${ }^{34} \mathrm{Cfr}$. el breve recorrido histórico que desarrolla Syliane Charles respecto de las tradiciones anglosajona y francesa como dos polos opuestos en este dilema, constituyendo aquélla la tradición derivada de Deleuze, se ha volcado sobre la opción continuista, de la cual la propia autora pretende constituir el punto culminante al identificar razón e intuición como una operación gnoseológica única, aunque escindible analíticamente (Cfr. S. Malinowski-Charles, loc. cit.).

${ }^{35}$ G. Deleuze, Spinoza: filosofía práctica, op. cit., p. 126.

${ }^{36}$ ET, I, def. iii.

${ }^{37}$ Interpretación a la cual más bien cabría denominar milagrosa, dado que, sin dar cuenta del origen espontáneo de las ideas (ideas adecuadas, en el pasaje de la opinión a la razón; idea de Dios, en el pasaje de la razón a la intuición) no admite ruptura alguna entre estos pasajes. A modo de ejemplo de esta estrategia — de larga data y característica al momento de analizar esta problemática-, $c f r$. V. Delbos, "Le Problème moral dans la philosophie de Spinoza", pp. 126-139.

Diánoia, vol. LIII, no. 60 (mayo 2008). 
de TB-TRE-ET: si, como apunta Cassirer, "no hay cadena argumentativa que lleve de lo finito a lo infinito", ${ }^{38}$ sino que lo infinito debe ser captado intuitive, nullam operationem facientes, ${ }^{39}$ y dado que la razón no puede operar el paso desde la consideración de los modos a la contemplación de Dios, es propio de la scientia intuitiva prescindir de la inferencia para llegar al conocimiento último de la sustancia. ${ }^{40}$

La intención de Spinoza al insistir sobre esta ruptura es clara: Dios no puede ser demostrado a posteriori — partiendo del efecto hacia la causa-, sino que es desde su concepto de donde debemos partir para demostrar la existencia necesaria de atributos y modos. En otras palabras, es justamente el objeto supremo del conocimiento el que instaura el límite del conocimiento indirecto. ${ }^{41}$ Sin ingresar en esa problemática, dado que los motivos y consecuencias de este desplazamiento respecto de la tradición aristotélico-tomista $-\mathrm{y}$, en segunda instancia, cartesiana - han sido profusamente comentados en la literatura spinozista, nos limitaremos a señalar, a modo de conclusión, los dos momentos que estructuran el tercer género de conocimiento como movimiento complejo: una vez en posesión de la idea adecuada de Dios -imposible de ser inferida de ninguna idea finita-, podremos deducir de ella una infinidad de cosas. En síntesis, si parece imposible asignar un carácter intuitivo a las operaciones por el tercer género una vez que poseemos la idea adecuada de Dios, igualmente imposible parece ser la negación del carácter intuitivo del proceso mediante el cual llegamos a esa idea: como apunta Amalia Bernardini, "para Spinoza el Absoluto es [...] el

${ }^{38}$ E. Cassirer, El problema del conocimiento, I, p. 9.

${ }^{39}$ TRE § 24.

${ }^{40}$ Aun cuando ciertos pasajes del TB parecerían permitir la interpretación contraria -es decir, que el ejercicio del segundo género de conocimiento conllevaría necesariamente una natural transición hacia el tercer género ("El razonamiento no es lo más excelso, sino como una escalera a través de la cual ascendemos al lugar deseado" TB, II, 26.6)—, no deja de ser significativo que la exposición del movimiento por el cual el alma llega a la idea de Dios, tal como aparece en TB (II, 22.5) y ET (II, 45, dem.), presupone ya el conocimiento del carácter no sustancial de los modos, que era precisamente quod erat demonstrandum, lo cual se conjuga perfectamente con la idea que anticipaba (proyectada en un lenguaje equívocamente místico) el mismo TB al hablar de un verdadero renacimiento (II, 22-23).

${ }^{41}$ Ésta parece ser la intención primordial manifiesta en $T B$ : "Es la causa de todo conocimiento, [...] es conocido únicamente por sí mismo y no mediante alguna otra cosa. Y aparte de eso, [...] estamos tan unidos con él que no podemos ni existir ni ser entendidos sin él; y de aquí se sigue claramente, a su vez, que, dado que nuestra unión con Dios es tan estrecha, no lo podemos conocer sino inmediatamente" (II, 22.3). 
primum cognitum, tanto que es del hombre, y no de Dios, que hay que demostrar la existencia". ${ }^{42}$

Como se hace evidente, esta reconstrucción parcial del tercer género no sólo no ha resuelto todos los interrogantes posibles, sino que ha abierto más de los que desearíamos. Que la idea de Dios opere como primum cognitum falla en un momento esencial: explicar, si ése es el caso, cómo es posible que exista el primer género de conocimiento. En todo caso, como se hace evidente en la confrontación entre TRE y ET, el orden de exposición no es el mismo que el orden de formación de los conceptos, ${ }^{43}$ y quizá haya razón en admitir el reconocimiento de esta divergencia como el motivo fundamental por el cual Spinoza habría de abandonar la redacción del TRE. En efecto, si éste describía el proceso de formación de las ideas adecuadas - proceso articulado sobre el incremento progresivo de la agendi potentia del alma-, un obstáculo pertinaz e insalvable afloraba en cada página: explicar la presencia en el alma de la idea de Dios (a la que hay que llegar quanto ocius), precisamente la idea a partir de la cual los dos tratados sistemáticos de ontología (TB y ET) establecen como punto de partida. En otras palabras, el reconocimiento de que la ontología (progresión/invención según un orden inmanente a partir de aquello que es causa de sí) no podía ser antecedida por un preludio gnoseológico. Como ya el TRE lo presentía —negándose a sí mismo y todavía con ciertas reminiscencias prescriptivas-, "el método más perfecto será el que muestre cómo el espíritu (mens) debe ser dirigido según la norma de la idea dada del Ser (entis) perfectísimo". ${ }^{4}$

Caillois ha intuido esta problemática con máxima lucidez, poniendo de manifiesto el núcleo más perturbador del determinismo:

Hay una cosa propiamente impensable que no está en el sistema: el sistema mismo. La Ética, libro perfecto, único, cerrado sobre sí mismo como una esfera donde se refleja la totalidad del ser, explica todo, salvo la presencia misma de la Ética. La única cosa que la esfera no refleja es su propio reflejo. Así, tal como un aerolito espiritual, la Ética ha caído del cielo, en no importa qué momento de la Historia para revelar el Ser. ${ }^{45}$

${ }^{42}$ A. Bernardini, "Spinoza: Dios como sustancia y causa sui", p. 367.

${ }^{43}$ De aquí que, mientras que la ET se inaugura con la definición de la sustancia, el proceso mediante el cual el alma llega a la idea de Dios se vea desarrollado recién en la proposición 45 de la Segunda Parte. Vid., a este respecto, G. Deleuze, Spinoza: filosofía práctica, p. 148.

${ }^{44}$ TRE § 38.

${ }^{45}$ R. Caillois, op. cit., p. 43; la traducción es nuestra. 


\section{Legalidad y singularidad en la definición de la esencia del alma}

Cuatro son, cuando menos, las precisiones metodológicas que exige el spinozismo para una teoría de la definición de los modos finitos: 1) la definición no debe "recurrir a algunas propiedades en lugar de la esencia"; 46 2) a partir de la definición se deben poder "concluir todas las propiedades de la cosa"; ${ }^{47} 3$ ) "Aquello que es común a todas las cosas, y que está igualmente en la parte y en el todo, no constituye la esencia de ninguna cosa singular"; 48 4) "La definición deberá comprender la causa próxima." 49

Si bien las dos primeras exigencias no merecen mayor atención (dado nuestro objetivo), es en la articulación entre las dos últimas donde encontramos la clave última para comprender la concepción específica de la singularidad de la esencia para Spinoza. Según el tercer precepto, la definición de la esencia de un modo finito no puede agotarse en la indicación de aquello que ese modo comparte con otras modificaciones del mismo atributo. Esto expresa ciertamente una exigencia que ya se había hecho presente al analizar el segundo género de conocimiento, el cual, a todo lo largo de TB-TRE-ET había demostrado que "los fundamentos de la razón son nociones que explican lo que es común a todas las cosas, y que no explican la esencia de ninguna cosa singular". ${ }^{50} \mathrm{En}$ virtud de esto, si el conocimiento del efecto depende del conocimiento de la causa, y dado que el modo no es causa de sí mismo, el cuarto precepto parece subsanar las limitaciones de la razón para dar cuenta de la singularidad y conducirnos hacia el umbral de la scientia intuitiva: "la definición deberá comprender la causa próxima". Sin embargo, en

${ }^{46} T R E$ § 95. En rigor, esta especificación (crítica abierta a Aristóteles, Tomás y Descartes) no es más que la constatación, como el propio Spinoza aclara, del principio lógico que afirma que para conocer las propiedades necesito conocer la esencia: "los accidentes [...] nunca se conocen claramente sin un conocimiento previo de la esencia" (§ 27).

${ }^{47} T R E \S$ 97. Cfr. ET, I, 16, dem.

${ }^{48} E T$, II, 37. Cfr. TB, I, 10.3: "Las cosas deben concordar con sus ideas particulares, cuyo ser constituye una esencia perfecta, y no con la idea general, ya que entonces ni existirían"; TRE § 55: "La diferencia que existe entre la esencia de una cosa y la esencia de otra es la misma que existe entre la actualidad o la existencia de esa misma cosa y la actualidad o existencia de otra cosa. De tal manera que si, por ejemplo, quisiéramos concebir la existencia de Adán sólo por la existencia en general, sería lo mismo que si, para concebir la esencia prestásemos atención a la naturaleza del ser (naturam entis) y definiésemos finalmente a Adán como un ser (definiamus Adamum esse ens)."

${ }^{49}$ TRE § 95. Cfr. ET, I, 8, esc. ii.

${ }^{50} E T$, II, 44, dem. 
el momento en que pedimos al TRE una explicitación de este procedimiento, encontramos un movimiento inesperado:

Por serie de las causas y de los seres (entium) reales no entiendo la serie de las cosas singulares mudables, sino tan sólo la serie de las cosas fijas y eternas. Sería imposible para la debilidad (imbecillitati) humana aferrar la serie de las cosas singulares mudables, tanto a causa de la multitud de las mismas, que supera todo número, cuanto por las infinitas circunstancias en una única y misma cosa; cada una de éstas puede ser causa de que la cosa exista o de que no exista, ya que la existencia de tales cosas no tiene ninguna conexión con su esencia o (como ya dijimos) no es una verdad eterna. Pero lo cierto es que tampoco es necesario que conozcamos tal serie, puesto que las esencias de las cosas singulares mudables no han de ser sacadas (depromendae) de su serie, o sea, de su orden de existencia, ya que éste no nos ofrece más que sus denominaciones extrínsecas, relaciones o, a lo sumo, circunstancias; y todas estas cosas distan mucho de ser la esencia (intima essentia) de las cosas. Ésta, al contrario, sólo ha de ser pedida a las cosas fijas y eternas, al mismo tiempo que a las leyes inscritas en esas cosas como en sus verdaderos códigos (tamquam in suis veris codicibus inscriptis), leyes según las cuales todas las cosas singulares llegan a ser y se ordenan. Más aún, estas cosas singulares mudables dependen tan íntima y esencialmente (por así decirlo) de las cosas fijas, que sin ellas no pueden ni ser, ni ser concebidas. De ahí que estas cosas fijas y eternas, aunque sean singulares, para nosotros serán, sin embargo, a causa de su presencia en todas partes y por su amplísima potencia (ubique praesentiam ac latissimam potentiam), como (tamquam) universales, o sea, como géneros de las definiciones de las cosas singulares mudables y como causas próximas de todas las cosas. ${ }^{51}$

Si a primera vista esta incorporación de la serie de las cosas fijas y eternas, a la que el conocimiento debe remitir en la búsqueda de la esencia del modo singular, parece no conciliarse demasiado bien con la exigencia de singularidad establecida por el tercer precepto, el resultado final es, antes que una contradicción, una articulación de dos elementos perfectamente compatibles: la mediación de las leyes eternas introduce en el proceso de producción de las esencias singulares un principio de ordenación que asegura el criterio de racionalidad e inteligibilidad en la expresión de la sustancia. Por otra parte, en caso de que las esencias fueran simples entidades singulares y completamente carentes de principios y leyes en común, nada podría predicarse de ellas: "Las cosas que no tienen nada en común una con otra, tampoco pueden entenderse una por otra, esto es, el concepto de una de ellas no implica el

${ }^{51}$ TRE $\S \S 100-101$. Cfr. una expresión similar de este principio en TB, I, 7.10. 
concepto de la otra." 52 En otras palabras, dado que todo conocimiento es conocimiento por la causa, sería imposible establecer ningún tipo de relación entre los modos de cada atributo, y el principio de inteligibilidad de la sustancia quedaría ipso facto impugnado. ${ }^{53}$ Más aún: si cualquier efecto pudiera seguirse de una causa dada, poco sentido tendría la elaboración de una Ética demostrada según el orden geométrico.

Bien es cierto que esta instancia eterna opera como si fuera el género de las esencias producidas, pero es precisamente en ese "como (tamquam)" que se manifiesta la posibilidad de articulación entre los dos preceptos: tales leyes no alcanzan a definir la esencia de un modo particular, pero la esencia de un modo particular no puede ser definida sin esas leyes. La serie de las cosas eternas encuentra su lugar aquí no como género que alcanzaría él solo para definir al modo, sino como una instancia productiva, de latissima potentia, que opera efectivamente como causa próxima, pero no suficiente. ${ }^{54} \mathrm{Si}$ tal serie no es la esencia de los modos, es preciso admitir que opera, actúa, para dar forma a la esencia de esos modos (de aquí que sea preciso "concluir [...] según cuáles leyes de las cosas eternas está hecha [...] para que su naturaleza íntima se nos dé a conocer"), ${ }^{55}$ pero preservando, simultáneamente, la singularidad de los mismos. En otras palabras, ninguna de las dos instancias (ni el orden singular de los modos ni las leyes que rigen a sus atributos) alcanza por sí sola para dar cuenta del carácter dual de las esencias de modo: absoluta singularidad y sujeción a una legalidad eterna. Dado el carácter monista-naturalista de la legalidad del sistema, la singularidad de las esencias no excluye su pertenencia a un orden legal universal; ${ }^{56}$ por el contrario, es sólo dentro de éste donde

${ }^{52} E T$, I, axioma v.

${ }^{53}$ La histórica filiación entre voluntarismo y nominalismo explica en buena parte este problema. Respecto de la inspiración cartesiana de ciertos argumentos spinozistas de carácter nominalista, cfr. R. Descartes, Principia, I, 57, 58, y el análisis realizado por Laurent Bove sobre la problemática del lenguaje en Spinoza (op. cit., pp. 16-33).

${ }^{54}$ Miller asigna una posible influencia cartesiana a esta concepción de la ley como instancia causal: "Para Spinoza [...] las leyes son miembros reales del mundo y ellas (junto con la serie de causas de las cuales todos los modos finitos son miembros) directamente determinan todo lo que acontece o existe" ( J. Miller, "Spinoza and the Concept of a Law of Nature", pp. 265-266 y nota 29; la traducción es nuestra).

${ }^{55}$ TRE § 103.

${ }^{56}$ Como afirma Paola de Cuzzani, "es solamente por una mistificación que uno puede pensarse a sí mismo [...] dotado de una naturaleza que sigue sus propias reglas, diferentes y separadas (détachées) de las leyes comunes del orden natural" 
la singularidad de las esencias podrá ser aprehendida, y sólo podremos conocer la esencia singular en tanto ésta sea localizada como expresión singular de un todo sujeto a leyes que, no agotándose en ser solamente eso, se ve determinada ulteriormente por las restantes modificaciones a través de la mediación de las leyes del atributo del que son, precisamente, modificaciones.

Bajo estas condiciones, se hace claro que la definición que buscamos del alma deberá considerar varios elementos: $(a)$ su relación con el atributo del que es una modificación; $(b)$ su relación con las leyes bajo las que tal atributo expresa la sustancia; (c) la singularidad de su esencia. El primero de estos elementos remite a dos razones fundantes en la ontología spinozista: la articulación entre (a1) el carácter modal del alma, que hace imposible toda consideración sustancialista de la misma, ${ }^{57}$ y (a2) la ausencia de toda consideración idealista/espiritualista del alma. ${ }^{58}$ La primera evidencia de este segundo posicionamiento la encontramos en el hecho de que, a diferencia del cuerpo, el alma no posee una definición propia en la lista de definiciones que encabeza la Parte Segunda de ET. En efecto, mientras que la primera de tales definiciones establece que un cuerpo es un "modo que expresa de cierta y determinada manera la esencia de Dios, en cuanto se la considera como una cosa extensa" ${ }^{59}$ cabría esperar —en función del paralelismo de los atributos- una definición análoga del alma como modo que expresa de cierta y determinada la esencia de Dios, en cuanto se la considera como una cosa pensante. Si esto no sucede, si tal definición está ausente, esto se debe a que el alma dice más que la simple modificación del atributo del pensamiento, ya que contiene formalmente las modificaciones

(P. de Cuzzani, “Une Anthropologie de l'homme décentré”, p. 10; la traducción es nuestra).

57 "Nuestra alma es una sustancia o un modo. No es sustancia, porque ya hemos demostrado que no puede existir en la naturaleza ninguna sustancia limitada. Luego es un modo." (TB, II, prefacio, nota v.i).

${ }^{58}$ Jon Miller ha sostenido implícitamente una interpretación idealista del alma, al afirmar que "human nature can be properly conceived in terms of the nature of the human mind" [la naturaleza humana puede concebirse apropiadamente en términos de la naturaleza de la mente del hombre]. Si éste fuera el caso, toda referencia a las leyes que rigen el atributo de la extensión se volvería por completo innecesaria. No obstante, el único pasaje de Spinoza que el autor refiere para fundamentar esta posición proviene de una errónea traducción de $E T$, IV, 26, esc., traduciendo humana essentia quatenus ratione definitur (la naturaleza humana en tanto definida por la razón) por "the very essence of man ... is defined by reason" ( J. Miller, "Spinoza's Axiology", pp. 164).

${ }^{59} E T$, II, def. i.

Diánoia, vol. LIII, no. 60 (mayo 2008). 
del atributo de la extensión. ${ }^{60} \mathrm{Si}$ con esto queda puesto en entredicho el carácter completamente hermético del paralelismo al establecer la intencionalidad del atributo del pensamiento, ${ }^{61}$ esto no significa, desde ya, la posibilidad de una determinación recíproca de los atributos, puesto que "ni el cuerpo puede determinar al alma a pensar, ni el alma puede determinar al cuerpo al movimiento ni al reposo, ni a otra cosa alguna". ${ }^{62}$ En consecuencia, "el objeto de la idea que constituye el alma humana es un cuerpo, o sea, cierto modo de la Extensión existente en acto, y no otra cosa". ${ }^{63}$

Con esto la singularidad de la esencia del alma (c) queda establecida en forma definitiva: la esencia del alma humana es la idea singular (aunque no simple) ${ }^{64}$ de un cuerpo singular existente en acto. Esto no sólo implica que a cada cuerpo singular corresponde un alma singular, sino que a cada modificación-afección del mismo corresponderá una modificación-afección del alma. ${ }^{65}$ Aunque en forma implícita, se hace evidente que ya no es posible seguir considerando el alma como forma universal del cuerpo; menos aún que el cuerpo opere como factor de diferenciación de entelequias eternas y puras que habrían de perder su identidad prístina al entrar en contacto con la carne. Por el contrario, a ambos (tanto al cuerpo como al alma) corresponden esencias singulares, y ambos están sometidos a leyes. Esta problemática ingresa en un terreno ciertamente oscuro aun si consideramos que a cada modo, no sólo del pensamiento (i.e., el alma) sino también de la extensión, corresponde una esencia: si lo que constituye la esencia del alma es la idea de un cuerpo existente (y de sus modificaciones), la

${ }^{60}$ La definición del alma como "un cierto modo del pensar" recién hará su aparición en el interior de la demostración de ET, II, 48, cuando el recorrido previo por la intencionalidad del cuerpo ha quedado plenamente explicitado.

${ }^{61}$ Cfr. E. Yakira, "Spinoza et le problème de l'intentionnalité", pp. 139-146, y Dossier "Spinoza et le corps".

${ }^{62}$ ET, III, 2.

${ }^{63} E T$, II, 13. En forma fugaz y sin desarrollos ulteriores (y sin que la doctrina del paralelismo estuviese todavía desplegada), el TB ya había insinuado esta implicación del cuerpo en el alma al señalar que "nuestra alma, al ser una idea del cuerpo, tiene del cuerpo su primer ser" (II, 22.5). Cfr. asimismo TB, apéndice II, 3.

64 "La idea que constituye el ser formal del alma humana es la idea del cuerpo, el cual se compone de muchísimos individuos muy compuestos. Ahora bien: hay (datur) necesariamente una idea en Dios de cada individuo componente de un cuerpo. Luego la idea del cuerpo humano está compuesta de esas numerosísimas ideas de sus partes componentes" (ET, II, 15, dem.).

${ }^{65}$ Para una conceptualización detallada de esta última relación, vid. G. Deleuze, Spinoza y el problema de la expresión, caps. XII-XIII. 
esencia de ese cuerpo estará constituida, a su vez, por una (singular y variable) relación de movimiento y reposo. ${ }^{66}$ Sin embargo, como señala Miller, ${ }^{67}$ no es posible deducir de esto, en virtud del paralelismo, que exista un dualismo de esencias, dado que ambas modificaciones son, en última instancia, expresiones de atributos que expresan, a su vez, a la sustancia una. Más aun, es esta identidad de fondo la que permite la complejidad de la pregunta por la natura humana, ${ }^{68}$ la cual ya no podrá ser definida por su sola pertenencia al plano de las ideas, sino que necesariamente implicará tanto sus propias afecciones como las del cuerpo, así como las leyes que rigen a ambos tipos de afecciones. Para establecer provisoriamente las implicaciones de esta proposición, cabe advertir el desplazamiento ocurrido aquí respecto de Descartes, quien afirmaba que "este yo, es decir, el alma, por la que soy lo que soy, es enteramente distinta del cuerpo; y hasta es más fácil de conocer que éste, y aunque él no existiese, ella no dejaría de ser aquello que es (ce qu'elle est)". ${ }^{69}$

En cuanto al carácter no sustancial del alma humana ( $a 1$ ), una pregunta puede orientarnos hacia una sistematización del pensamiento de superficie que estructura la ontología spinozista: si la sustancia no es más que sus expresiones infinitas, ¿podemos hacer extensivo el mismo argumento a la definición del alma? Es decir, ¿es el alma algo más que una collectio de ideas? Si así fuera, si el alma no fuera más que el lugar donde las ideas se hacen presentes, deberíamos inmediatamente declarar la imposibilidad de pretender encontrar alguna instancia de universalidad en la consideración de la naturaleza humana. Más aun,

66 "Los cuerpos se distinguen entre sí en razón del movimiento y el reposo, de la rapidez y la lentitud (motus et quietis, celeritatis et tarditatis), y no en razón de la substancia" ( $E T$, II, 13, lema iii). Una formulación similar recibe la esencia del cuerpo en TB, II, prefacio, 5, nota 5, y en Apéndice II, 14-15, donde la hallamos superpuesta a la doctrina (de resurgimiento periódico desde los presocráticos hasta el Renacimiento) de la identificación fisiológica entre calor/frío y estados del alma activos/pasivos.

${ }^{67}$ Cfr. J. Miller, "Spinoza's Axiology”, op. cit., p. 155.

${ }^{68} \mathrm{Si}$ "primum quod actuale mentis humanæ esse constituit, nihil aliud est quam idea rei alicujus singularis actu existentis" (ET, II, 11), esto significa que, por ser modo del atributo del pensamiento, el alma es idea; pero es siempre idea de algo. Ahora bien, este algo no puede ser infinito, sino de "una cosa existente en acto". Por lo tanto, "la idea que constituye el alma humana es un cuerpo" (ET, II, 13, dem.). En otras palabras, el Discours de la méthode no debería haber comenzado por la idea de Dios presente en el alma, sino por la salamandra que animaba las noctes cartesianae, mediada por el cuerpo del francés.

${ }^{69}$ R. Descartes, Discours, AT VI, 33; la traducción es nuestra. 
sería forzoso reconocer que esta última noción carece por completo de sentido, y que una ética que pretende dilucidar principios de regularidad en las acciones y reacciones anímicas sería una empresa destinada al fracaso. Si bien la posibilidad de considerar al alma como un mero locus ha sido defendida con frecuencia, ${ }^{70}$ creemos evidente que esto no alcanza para definir su condición esencial: el alma es, efectivamente, una collectio de ideas, pero estas ideas se implican mutuamente según un encadenamiento específico y necesario, tanto si se trata de ideas adecuadas como inadecuadas, mutiladas y confusas. No obstante -dando respuesta a la pregunta $(b)$ acerca de la relación del alma con las leyes del atributo del pensamiento-, aun cuando sean las leyes del ese atributo (del cual el alma no es más que una modificación) las que determinen en forma universal las acciones y pasiones del alma, debe evitarse el extremo inverso de la posición que desechamos antes (el alma como simple locus); es decir, considerar que el alma es nada más que una legalidad formal, vacía y previa a las ideas. Por el contrario, son esas mismas ideas las que instauran su propia e inmanente causalidad: "la idea de una cosa singular es causa de otra idea, o sea, Dios en cuanto se lo considera afectado por otra idea, y también de ésta en cuanto es afectado por otra, y así hasta el infinito". ${ }^{71}$

${ }^{70}$ Vid., a modo de ejemplo, F. Tinland, "Spinoza ou la force d'affirmer", p. 58.; C.A. Van Peursen, "La Critère de la vérité chez Spinoza", p. 522.; P. de Cuzzani, op. cit., pp. 16-17; A. Zaninetti, "L'Importance du mécanisme de projection imaginatif au sein de la démarche éthique spinozienne", p. 16; F. Lordon, "Revenir à Spinoza dans la conjoncture intellectuelle présente", p. 17 (lectura estructuralista, esta última, que precisa una interpretación del alma como lugar vacío, como simple punto de intersección de fuerzas, para hacer plausible la lectura althusseriana de Spinoza). Paul Eisenberg ha insistido sobre el error implícito en esta interpretación, sin ofrecer, no obstante, una solución definitiva a la pregunta inicial de qué es, a fin de cuentas, el alma: "A pesar de que frecuentemente Spinoza habla en TRE (así como en sus escritos posteriores) de la ideas como estando en el entendimiento o el alma como sus productos, no se debe suponer que él realmente concibiera el entendimiento o el alma como una especie de receptáculo espiritual que sería (por así decirlo) el lugar natural de las ideas, ni siquiera como una 'facultad' real distinta de los pensamientos singulares que serían sus manifestaciones o efectos. Sin embargo, no debemos volvernos demasiado en el sentido contrario y suponer que para Spinoza el alma es simplemente un hatajo (bundle) de ideas [...] y que el entendimiento no es más que el nombre colectivo que designa las ideas o percepciones que conforman ese hatajo. [...] El entendimiento no es, después de todo, meramente una multitud de ideas particulares amontonadas juntas o dispersas entre otras ideas particulares en un alma que no sería más que la suma aritmética de las ideas individuales" (P.D. Eisenberg, op. cit., p. 189; la traducción es nuestra).

${ }^{71}$ ET, II, 9, dem. 
Si hemos eludido hasta ahora toda mención al conatus como esencia del hombre, esto se debe a que lo mismo que hemos dicho respecto de la relación entre el alma y las ideas debe ser dicho en cuanto a la relación del alma con el conatus, el cual es una tendencia presente en el alma, y no una forma de la misma. Si "el esfuerzo o potencia (conatus sive potentia) del alma es la esencia misma de ese alma", ${ }^{72}$ esto se debe a su subsistencia en el alma más allá de las afecciones que ésta reciba, más allá de las ideas que se hagan presentes en la misma. En otras palabras, el conatus es el fondo mismo contra el que habrá de imprimirse toda idea e imagen que quiera hacerse presente en el alma. Es él, en última instancia, quien -a pesar de su falibilidad- decidirá el lugar que éstas habrán de ocupar en la determinación de las acciones y las pasiones. En tal caso, dado que el alma es una potencia (en términos deleuzianos, susceptible de ser colmada o vaciada), se hace manifiesto un nuevo motivo que, al tiempo que refuerza el distanciamiento respecto del platonismo-aristotelismo-tomismo, impugna la consideración de la misma como entidad eterna e inmutable, forzando a considerarla más bien como un estado, una relación de fuerzas o configuración temporal. No habiendo un alma-sustrato con facultades diversas, el alma sólo pueda ser concebida como el pasaje desde una disposición pasiva a una activa (o a la inversa); pero esto sólo bajo la condición de que tales pasajes incorporen la mediación de las leyes del atributo. Si así no sucediera, es decir, si la definición de la naturaleza del alma se limitara a constatar la presencia en la misma del conatus quo unaquæque res in suo esse perseverare conatur, quedaría desestimado el principio que afirmaba que "aquello que es común a todas las cosas, y que está igualmente en la parte y en el todo, no constituye la esencia de ninguna cosa singular", ${ }^{73}$ dado que el conatus no constituye el elemento definitorio de la naturaleza o esencia humana en particular, sino de todo ente existente.

De aquí que la negación del carácter sustancial del alma humana y la afirmación de la singularidad de las esencias no implique una adhesión inmediata e incondicional a una posición nominalista extrema. Como lo resume Deleuze, "Spinoza no ataca lo universal, sino solamente una cierta concepción de lo universal abstracto". ${ }^{74}$ Los termini transcendentales y universales abstractos —productos de la imaginación y de origen sensible- que el parcial ataque nominalista de Spinoza pone en cuestión, no abandonan al pensamiento sobre el terreno inestable de un

${ }^{72} E T$, III, 54.

${ }^{73} E T$, II, 37.

${ }^{74}$ G. Deleuze, Spinoza y el problema de la expresión, op. cit., p. 270. 
lenguaje precario: si el determinismo spinozista reorienta la pregunta por la causalidad fuera del plano de la determinación aristotélica por géneros, para inscribirla en el plano de la serie de determinaciones singulares que preceden y configuran a toda instancia singular, esto no alcanza para establecer la esencia de los entes singulares, ya que ésta ha de ser buscada, complementariamente, en las leyes que regulan tales determinaciones. Elevándose en la escala de la prioridad lógica, el $T B$ había desembocado en el movimiento (y el reposo) como modo infinito inmediato de la extensión y en el entendimiento infinito como modo infinito inmediato del pensamiento. Las leyes que atraviesan al movimiento y al reposo jamás habrán de ser obtenidas por vía de la inducción y de la generalización a partir de instancias singulares, sino que habrán de ser deducidas de los elementos simples de la física. ${ }^{75}$ De modo análogo, la instancia mediante la cual habrá de ser explicada y comprendida toda idea particular, en lugar de consistir en una abstracción de las generalidades recurrentes en una serie finita de casos, habrá de ser deducida de los axiomas mismos que la ET provee como los elementos más simples

${ }^{75}$ Jon Miller ha intentado una extensa justificación del carácter universal y naturalista de la legalidad spinozista: luego de establecer una clasificación de las leyes que estructuran el universo spinozista en cuatro niveles diferenciados por su dominio o intencionalidad (1. aquellas cuyo dominio se restringe a individuos singulares; 2 . aquellas que comprenden grupos de individuos o especies; 3 . aquellas que involucran a individuos de diferentes grupos o especies; 4. aquellas cuyo dominio es la naturaleza considerada como totalidad), propone como clave inicial de interpretación de la relación entre los distintos niveles el carácter no anidado (not nested) de las leyes menos universales en relación con aquellas de niveles superiores. Aun así, el autor no parece interpretar esto como un obstáculo para llegar a la conclusión final de su trabajo, la cual afirma que, en última instancia, el sistema spinozista estaría estructurado bajo la forma de una metodología nomológico-deductiva ( J. Miller, "Spinoza and the Concept of a Law of Nature", pp. 260-265). En contra de esto, creemos que es precisamente el carácter inclusivo de las leyes de orden superior respecto de las de los órdenes inferiores lo que asegura la sistematicidad del sistema spinozista. Si bien esto no supone hacer extensivas a un atributo las leyes que rigen a otro, consideramos más que evidente que las leyes que rigen a la sustancia como totalidad deben necesariamente comprobarse para el caso de los atributos y los modos, lo cual obliga a reformular la clasificación de Miller (esclava del concepto de especie) bajo criterios de derivación ontológica: 1) existen leyes específicas del alma como conjunto de ideas encadenadas lógicamente; 2) en tanto el alma es una idea de un cuerpo existente en acto, la legalidad del alma debe comprender de algún modo las leyes de reposo y movimiento que rigen a los cuerpos; 3) siendo una modificación de un atributo específico, debe regirse por las leyes que rigen a ese atributo; 4) siendo una modificación de un atributo de la sustancia, debe regirse por las leyes que rigen a la sustancia. 
a partir de los cuales una recomposición del modelo de la naturaleza podrá ser alcanzada.

En última instancia, dejando de lado el hecho de que la alusión a la natura humana puebla en forma casi excesiva no sólo los escolios sino también las demostraciones de $E T^{76}$ (lo cual constituye una impugnación fáctica de la negación nominalista extrema de toda instancia universal o, cuando menos, predicable de un grupo de individuos), ${ }^{77}$ difícilmente podría ser establecido un objetivo más importante para la redacción de ET que la deducción necesaria de las leyes que determinan la naturaleza humana:

Nada ocurre en la naturaleza que pueda atribuirse a vicio de ella; la naturaleza es siempre la misma, y es siempre la misma, en todas partes, su eficacia y potencia de obrar (virtus et agendi potentia); es decir, son siempre las mismas, en todas partes, las leyes y reglas naturales según las cuales ocurren las cosas y pasan (mutantur) de unas formas a otras; por tanto, uno y el mismo debe ser también el camino para entender la naturaleza de las cosas (ratio rerum), cualesquiera que sean, a saber: por medio de las leyes y reglas universales de la naturaleza. ${ }^{78}$

${ }^{76}$ Cfr. especialmente I, 8, esc. ii; III, 32, esc.; III, 42, esc.; IV, 29, dem.; IV, 35, dem.; IV, 61, dem. Fuera de ET, cfr. TRE $\S \S 13,25,58,108 ;$ TTP, pp. 46, 61, 189; TP, II.15; IV.3-8; VI.3; Cartas XVII y XIX.

${ }^{77}$ Cfr., a este respecto, la definición más explícita del concepto de lex en la obra de Spinoza: "La palabra ley, tomada en sentido absoluto, significa aquello por lo cual los individuos de una misma especie [...] actúan de una misma forma, fija y determinada" (TTP, p. 57). En contra de esto, ciertos pasajes de ET parecerían avalar una interpretación de la naturaleza humana como singularidad absoluta: "Cada cual apetece o aborrece necesariamente, en virtud de las leyes de su naturaleza (ex legibus suæ naturæ), lo que juzga bueno o malo" (IV, 19); "Nadie se esfuerza en conservar su ser sino en virtud de las leyes de su propia naturaleza (ex propriæ suæ naturæ legibus)" (IV, 18, esc); "Padecemos cuando en nosotros se produce algo cuya causa somos sólo parcialmente, esto es, algo que no puede deducirse de las solas leyes de nuestra naturaleza (ex solis legibus nostræ naturæ)" (IV, II, dem.). Sin embargo, se hace evidente que de lo que se trata es en realidad de una elipsis de una figura universal. Así, en IV, ap., 7, encontramos que "si convive con individuos que concuerdan con su propia naturaleza de hombre (ipsius hominis natura), su potencia de obrar resultará mantenida y estimulada". Esta última conjunción entre "naturaleza propia" (ipsius) y "naturaleza de hombre" (hominis natura) es suficiente -creemos - para impugnar cualquier interpretación que pretenda desentenderse de toda instancia universal que trascienda la singularidad de los modos finitos.

${ }^{78}$ ET, III, prefacio. Idéntica centralidad puede ser señalada respecto de la construcción política en TP: "Aplicándome a los problemas políticos no pretendo descubrir nada nuevo o inédito. He tratado de explicar de una manera rigurosa e indis- 


\section{Conclusión}

A lo largo de estas páginas hemos intentado ofrecer un número de elementos que juzgamos decisivo para desterrar toda interpretación nominalista de la ética de Baruch Spinoza. Esto ha sido realizado mediante una progresión articulada de argumentos: en primer lugar, hemos traído a la luz la evidencia textual presente en la obra de Spinoza que permite poner de manifiesto que aun las nociones comunes poseen un incuestionable grado de universalidad y necesidad; esto es, que remiten a un ordenamiento ontológico objetivo: de otra forma, toda afirmación respecto de la naturaleza humana que pretendiera reclamar algún tipo de validez que trascienda la mera singularidad carecería por completo de fundamentos.

A partir de allí hemos deducido una conclusión ulterior: la obra de Spinoza no constituye un intento de expulsar de la reflexión filosófica el concepto de naturaleza humana, sino que, por el contrario, pretende refundar la ética sobre una humana natura que no esté ya construida arbitrariamente a partir del orden de la imaginación, sino sobre un modelo construido a partir de las leyes (universales y eternas) que rigen a los modos. En función de esta última premisa hemos ofrecido un desarrollo parcial de la articulación entre las dos instancias exigidas para la comprensión de la esencia de los modos finitos: singularidad y subordinación a una legalidad de carácter universal y necesario.

Creemos haber hecho evidente mediante este desarrollo la necesidad de comprender que toda interpretación nominalista de la ética spinozista se construye en principio sobre dos elementos sumamente cuestionables: en primer lugar, la arbitraria extensión de la crítica del autor a la concepción abstracta de los conceptos universales (pertenecientes al orden de la imaginación) hacia el plano de las nociones comunes (pertenecientes al orden de la razón); en otras palabras, el error de suponer (contra la propia letra de Spinoza) que es imposible adjudicar universalidad a las nociones comunes. En segundo lugar (dificultad derivada de la primera), no haber comprendido el papel estructurante que asume el concepto de humana natura en la construcción de la ética spinozista, centralidad que descansa precisamente en el carácter universal que le otorga la doble pertenencia al orden de la singularidad y al de la legalidad universal.

Finalmente, hemos demostrado que es en el ingreso al tercer género de conocimiento y en la vida racional donde se muestra la posibilidad cutible, y según la condición de la naturaleza humana (ex ipsa humanae naturae conditione), la doctrina que mejor puede coincidir con la práctica" (TP, I.4). 
de reasumir esta doble pertenencia de todo modo finito a una naturaleza singular que no es más que una particularización inclusiva de la naturaleza humana general. ${ }^{79}$ Desatender cualquiera de estos dos órdenes (así como la articulación que hemos establecido entre ellos a través de las exigencias spinozistas respecto de una teoría de la definición), significa, o bien reconducir la ética spinozista hacia una reflexión nominalista anacrónicamente cercana a nuestra posmodernidad, o bien reducirla a un mero resabio aristotélico.

\section{BIBLIOGRAFÍA}

Adam, Charles; Paul Tannery (eds.), Oeuvres de Descartes, París, Vrin, 1956, 12 vols.

Bernardini, Amalia, "Spinoza: Dios como sustancia y causa sui", Revista de Filosofía de la Universidad de Costa Rica, vol. 56, no. 42, 1978, pp. 363-370.

Bove, Laurent, "La Théorie du langage chez Spinoza", L'Enseignement philosophique, año 41, no. 4, marzo-abril de 1991, pp. 16-33.

Cassirer, Ernst, El problema del conocimiento en la filosofía y en la ciencia modernas, trad. Wenceslao Roces, Fondo de Cultura Económica, México, 1993.

Cuzzani, Paola De, "Une Anthropologie de l'homme décentré", Philosophiques (Société de Philosophie du Québec), vol. 29, no. 1, 2002, pp. 7-21.

Delbos, Victor, "Le Problème moral dans la philosophie de Spinoza", Revue de Métaphysique et de Morale (Armand Collin), vol. 51, no. 1, 1944, pp. 126139.

Deleuze, Gilles, Spinoza y el problema de la expresión, trad. Horst Vogel, Muchnik, Barcelona, 1996.

— Spinoza: filosofía práctica, trad. Antonio Escohotado, Tusquets, Barcelona, 1984.

Dossier "Spinoza et le corps", Astérion (École Normale Supérieure Lettres et Sciences Humaines de Lyon), no. 3, septiembre de 2005, pp. 9-172.

Eisenberg, Paul D., "How to Understand De Intellectus Emendatione", en Genevieve Lloyd (comp.), Spinoza. Critical Assessments, I: Context, Sources and the Early Writings, Routledge, Londres, 2001.

Friedman, Joel, "An Overview of Spinoza's 'Ethics' ", Synthese (Dordrecht), vol. 37, no. 1, 1986, pp. 67-106.

Fuentes Herreros, José Luis, "Spinoza: una filosofía barroca", Logos (México), vol. 23, no. 69, 1995, pp. 11-48.

79 “Los hombres que viven según la guía de la razón obran necesariamente lo que necesariamente es bueno para la naturaleza humana y, por consiguiente, para cada hombre, esto es, lo que concuerda con la naturaleza de cada hombre" (ET, IV, 35, dem.).

Diánoia, vol. LIII, no. 60 (mayo 2008). 
Galichet, François, "Le Problème de l'illusion chez Spinoza", Revue de Métaphysique et de Morale (Armand Collin), año 77, no. 1, enero-marzo de 1972, pp. 1-19.

Gebhardt, Carl, Spinoza, traducción de Oscar Cohan, Losada, Buenos Aires, 1977.

Gilead, Amihud, "Spinoza's Principium Individuationis and Personal Identity", International Studies in Philosophy (Nueva York/Turín), vol. 15, no. 1, 1983, pp. 41-57.

Haserot, Francis S., "Spinoza and the Status of Universals", en Paul Kashap (comp.), Studies in Spinoza, University of California Press, Berkeley, 1974, pp. 43-67.

Lordon, Frédéric, "Revenir à Spinoza dans la conjoncture intellectuelle présente", L’Année de la régulation (Presses de la Fondation Nationale de Sciences Politiques), no. 5, 2001, pp. 1-20.

Malinowski-Charles, Syliane, "The Circle of Adequate Knowledge: Notes on Reason and Intuition in Spinoza", en Daniel Gerber y Steven Nadler (comps.), Oxford Studies in Early Modern Philosophy, Oxford University Press, Oxford, 2004.

Miller, Jon, "Spinoza and the concept of a law of nature", History of Philosophy Quarterly, vol. 20, no. 3, julio de 2003, pp. 257-276.

—_ "Spinoza's Axiology", Oxford Studies in Early Modern Philosophy, vol. 2, 2004, pp. 149-172.

Spinoza, Baruch, Ética demostrada según el orden geométrico, trad., introd. y notas de Vidal Peña, Orbis, Buenos Aires, 1984.

— Oeuvres completes, traducciones y notas de Roland Caillois, Madeleine Fancès y Robert Misrahi, Gallimard, París, 1954.

—, Opera, Carl Winters, Heidelberg, 1925.

—, Tratado breve, trad., pról. y notas de Atilano Domínguez, Alianza, Madrid, 1990.

—- Tratado de la reforma del entendimiento y otros escritos, trad., notas y comentario de Lelio Fernández y Jean Paul Margot, Universidad Nacional de Colombia, Colombia, 1984.

—_, Tratado político, trad. y estudio preliminar de Enrique Tierno Galván, Tecnos, Madrid, 1996.

— Tratado teológico-político, trad., introd., notas e índices de Atilano Domínguez, Alianza, Madrid, 1986.

Tatián, Diego, La cautela del salvaje. Pasiones y política en Spinoza, pról. Remo Bodei, Adriana Hidalgo, Buenos Aires, 2001.

Tinland, Franck, "Spinoza ou la force d'affirmer", Revue de Métaphysique et de Morale (Armand Collin), año 83, no. 1, enero-marzo 1978, pp. 51-72.

Van Peursen, C.A., "La Critère de la vérité chez Spinoza", Revue de Métaphysique et de Morale (Armand Collin), año 83, no. 4, octubre-diciembre de 1978, pp. 518-525. 
Yakira, Elhanan, "Spinoza et le problème de l'intentionnalité", Philosophiques (Société de philosophie du Québec), vol. 29, no. 1, 2002, pp. 139-146.

Zaninetti, Andrea, "L'importance du mécanisme de projection imaginatif au sein de la démarche éthique spinozienne", Philosophiques (Société de Philosophie du Québec), vol. 29, no. 1, 2002, pp. 99-105.

Recibido el 16 de febrero de 2006; aceptado el 30 de agosto de 2007. 